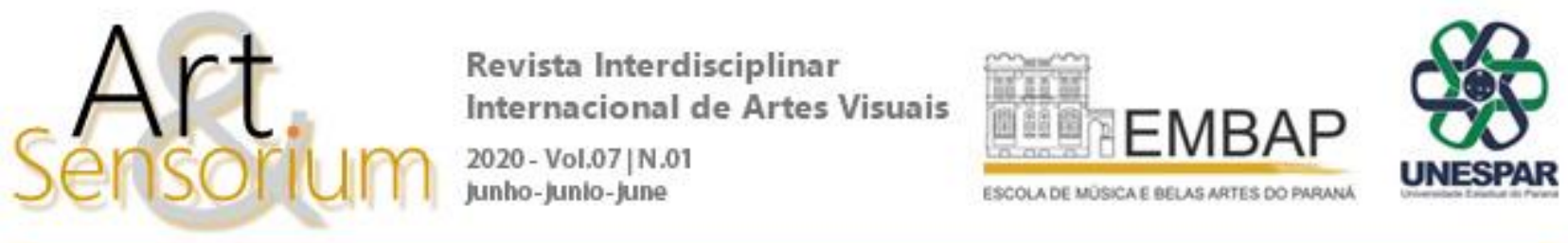

\title{
REFLEXÕES SOBRE EXPERIÊNCIAS DO ENSINO DAS ARTES VISUAIS COM ADOLESCENTES EM CONFLITO COM A LEI
}

DOI: https://doi.org/10.33871/23580437.2020.7.1.1-15

Resumo: Este artigo é um fragmento das experiências desenvolvidas na pesquisa do mestrado com o objetivo de reflexão e sobre experiências do Ensino das Artes Visuais com adolescentes em conflito com a lei, no Centro de Internação Feminina (CIF), em Florianópolis, Brasil. Este estudo visa compartilhar saberes sobre a Arte em espaços tolhidos de liberdade, como artista, pesquisador e educador, com o objetivo de ressignificar memórias e experiências singulares e estéticas das adolescentes reclusas. Consideram-se as conexões entre a narrativa verbal e oral das suas experiências, com o desenvolvimento de microprática com a monotipia, a cianotipia, a fotografia, a pintura e o desenho como formas de expressão artística e percepção de si e do contexto de suas reminiscências. Nesse sentido, procuram-se conceitos nos estudos teóricos de Almeida (2009), Barbosa (1991), Bergson (2010), Irwin (2013), Baudrillard (2004), Foucault (2014), Eisner (2011), Benjamin (1995), Freire (1996) e Dewey (2012), que abordam questões referentes à presente pesquisa. Utiliza-se a $\mathrm{A} / \mathrm{r} /$ tografia como metodologia de hibridização entre a narrativa contextualizada e a linguagem visual. Demonstram-se dois movimentos: um sobre os trabalhos artísticos e narrativas sobre memórias e experiências elaboradas pelas adolescentes, e outro, no encontro de experiências, reflexões críticas, observações e percepções como artista-pesquisadorprofessor. Nesse contexto, a pesquisa de campo buscou encontrar respostas e perguntas, proporcionando intersecções na construção de novas subjetividades e ressignificações por meio do Ensino das Artes Visuais nesses espaços não acadêmicos. Verificou-se que as adolescentes observaram suas experiências ressignificadas pelos processos artísticos, propiciando reconstruir identidades, expressões criadoras, autoestimas e refletir e interpretar os trabalhos produzidos e o próprio mundo.

Palavras-chave: Ensino das Artes Visuais; Reminiscências; Experiências singulares; Adolescentes reclusas; Artista-pesquisador-professor.

\section{REFLECTIONS ON EXPERIENCES OF TEACHING VISUAL ARTS FOR ADOLESCENTS IN CONFLICT WITH THE LAW}

Abstract: This article is a fragment of the experiences developed in master's research with the objective of reflection and on visual arts teaching experiences with adolescents in conflict with the

\footnotetext{
${ }^{1}$ https://orcid.org/0000-0002-2138-6366. Doutorando em Artes Visuais - PPGAV - Universidade do Estado de Santa Catarina UDESC - Florianópolis, Santa Catarina, Brasil.jokafloripa@gmail.com
}

R. Inter. Interdisc. Art\&Sensorium, Curitiba, v.7, n.1, p. 001 - 015 Jan.- Jun. 2020 
law at the Centro de Internação Feminina (CIF), in Florianópolis, Brasil. This study aims to share knowledge about art in tolhidos spaces of freedom, such as artist, researcher and educator, with the objective of remeaning memories and unique and aesthetic experiences of reclusive adolescents. The connections between the verbal and oral narrative of his experiences, with the development of micropractice with monotypia, cynotipia, photography, painting and drawing are considered as forms of artistic expression and perception of oneself and the context of its reminiscences. In this sense, concepts are sought in the theoretical studies of Almeida (2009), Barbosa (1991), Bergson (2010), Irwin (2013), Baudrillard (2004), Foucault (2014), Eisner (2011), Benjamin (1995), Freire (1996) and Dewey (2012), which address issues related to present research. A/r/tography is used as a hybridization methodology between contextualized narrative and visual language. Two movements are demonstrated: one about the artistic and narrative works on memories and experiences elaborated by adolescents, and the other, in the encounter of experiences, critical reflections, observations and perceptions as an artist-researcher-teacher. In this context, the field research sought to find answers and questions, providing intersections in the construction of new subjectivities and resignifications through visual arts teaching in these non-academic spaces. It was found that the adolescents observed their experiences resignified by artistic processes, providing reconstruction identities, creative expressions, self-esteem and reflect and interpret the works produced and the world itself.

Keywords: Teaching the Visual Arts; Reminiscences; Unique experiences; Reclusive teenagers; Artist-researcher-teacher.

\section{REFLECCIONES SOBRE EXPERIENCIAS DE ARTES VISUALES DE ENSAYO CON ADOLESCENTES EN CONFLICTO CON LA LEY}

Resumen: Este artículo es un fragmento de las experiencias desarrolladas en la investigación de maestría con el objetivo de la reflexión y sobre las artes visuales enseñando experiencias con adolescentes en conflicto con la ley en el Centro de Internação Feminina (CIF), en Florianópolis, Brasil. Este estudio tiene como objetivo compartir conocimientos sobre el arte en espacios tolhidos de libertad, como artista, investigador y educador, con el objetivo de resignificar recuerdos y experiencias únicas y estéticas de adolescentes solitarios. Las conexiones entre la narrativa verbal y oral de sus experiencias, con el desarrollo de la micropridad con monotipia, la citopia, la fotografía, la pintura y el dibujo se consideran formas de expresión artística y percepción de uno mismo y el contexto de su reminiscencias. En este sentido, se buscan conceptos en los estudios teóricos de Almeida (2009), Barbosa (1991), Bergson (2010), Irwin (2013), Baudrillard (2004), Foucault (2014), Eisner (2011), Benjamin (1995), Freire (1996) y Dewey (2012), que abordan cuestiones relacionadas con la investigación actual. La termografía se utiliza como metodología de hibridación entre la narrativa contextualizada y el lenguaje visual. Se demuestran dos movimientos: uno sobre los trabajos artísticos y narrativos sobre recuerdos y experiencias elaboradas por adolescentes, y otro, en el encuentro de experiencias, reflexiones críticas, observaciones y percepciones como artista-investigador-profesor. En este contexto, la investigación de campo buscó encontrar respuestas y preguntas, proporcionando intersecciones en la construcción de nuevas subjetividades y resignificaciones a través de la enseñanza de artes visuales en estos espacios no académicos. Se encontró que los adolescentes observaron sus experiencias resignadas por procesos artísticos, proporcionando identidades de reconstrucción, expresiones creativas, autoestima y reflejan e interpretan las obras producidas y el mundo mismo.

Palabras clave: Enseñar las Artes Visuales. Reminiscencias; Experiencias únicas; Adolescentes solitarios; Artista-investigador-profesor.

R. Inter. Interdisc. Art\&Sensorium, Curitiba, v.7, n.1, p. 001 - 015 Jan.- Jun. 2020 


\section{Introdução}

Historicamente, a Arte sempre esteve presente nas ações da humanidade, deixando registros das suas primeiras manifestações artísticas retratadas pelas pinturas nas paredes das cavernas, nos objetos, nos templos, nos costumes, nos hábitos e nos instrumentos, como meio de expressão de suas vivências e de pensamento. Esses indicativos revelam-nos a ligação entre a ação da pessoa e sua manifestação da Arte, como artista, pesquisador e professor. A Arte apresenta inúmeras ressignificações, novas formas e conteúdos ao longo do tempo, lugar e espaço. Nesse contexto, este estudo partiu do intuito de compartilhar e vivenciar saberes sobre a Arte em espaços tolhidos de liberdade, com objetivo de trocar experiências singulares e estéticas e ressignificar memórias das adolescentes reclusas, por meio do desenvolvimento de processos artísticos proposto no Plano de Ensino - Arte Educação, no ensino de artes visuais, específico para esta pesquisa, considerando a narrativa contextualizada, a monotipia, a cianotipia, fotografia, e o desenho como formas de expressão e percepção de ser e estar no mundo.

O local de pesquisa de campo foi o Centro de Internação Feminina (CIF), instituição pública que mantém em regime fechado adolescentes em conflito com a lei, com idade de 15 a 21 anos, na cidade de Florianópolis, Santa Catarina, onde, com a pesquisa, procurou-se encontrar respostas para obtenção de experiências durante o seu desenvolvimento, com o objetivo de observar, investigar e colher diretamente dados com o grupo de pesquisa formado por oito participantes reclusas.

Desse modo, foi planejado o uso de materiais artísticos e narrativas contextualizadas verbalmente pelas próprias jovens adolescentes como arsenal pedagógico a partir do entendimento do seu contexto. Com base no Plano de Ensino Arte Educação proposto para oito encontros, investigou-se as contribuições dos processos artísticos como forma de abrigar experiências com a Arte, motivando relações cognitivas e afetivas das memórias e experiências singulares e estéticas no processo de construção e valorização do conhecimento. Cada encontro recebeu um título referente ao tema abordado:

1) Conceitos de Arte;

2) Rememoração e contextualização das lembranças de experiências singulares;

3) Relatos de fragmentos de experiências singulares;

4) Construção de imagens das experiências vivenciadas pelo processo de monotipia;

5) Ressignificações de memórias de imagens por meio da técnica de cianotipia;

6) A fotografia como registro;

7) Desenho em linhas;

8) Reflexão e crítica dos trabalhos realizados.

Com base no Plano de Educação para o Ensino das Artes Visuais proposto, os encontros das micropráticas contemplaram os exercícios com a prática de diversos processos artísticos, desenvolvidos pelas participantes. Uma exposição dos trabalhos no final dos encontros foi realizada na própria instituição, bem como uma avaliação pelos participantes e visitantes dos resultados alcançados dos trabalhos no presente estudo.

As perguntas que foram dirigidas às adolescentes constam em questionários com o propósito de obter respostas e posicionamento das participantes quanto aos seus entendimentos e conhecimentos

R. Inter. Interdisc. Art\&Sensorium, Curitiba, v.7, n.1, p. 001 - 015 Jan.- Jun. 2020 
sobre Arte, suas participações nas micropráticas, bem como na produção dos trabalhos desenvolvidos durante os encontros.

Nesse sentido, propiciou-se que as adolescentes não só falem de si e de seu mundo, de suas imagens, de experiências, de memórias, de histórias de vida e de seus sonhos, mas também que apliquem seus próprios elementos de linguagem e expressão, formas e narrativas.

Utilizou-se a metodologia da $\mathrm{A} / \mathrm{r} / \mathrm{t} /$ grafia como forma de estimular a busca do entre e o dentre as práticas do fazer Arte, pesquisar e ensinar com experiências pessoais mediante o processo artístico para investigar e demonstrar o pensamento visual, tendo como referencial teórico a educadora de Arte Rita L. Irwin.

Ocorreram perguntas problematizadas: O que o Ensino das Artes Visuais pode propiciar a jovens adolescentes reclusas? É possível ensinar Arte para adolescentes sem liberdade? Há métodos específicos de Ensino das Artes Visuais para obter resultado independente do tempo e espaço? É possível expressar memórias e experiências ressignificadas por meio do processo artístico? O que as lembranças da memória representam para as pessoas? Saudade? Medo? Alegria? Com essas perguntas, procurou-se encontrar respostas nos teóricos pesquisados e no desenvolvimento das ações programadas.

Foi desenvolvida uma programação de oito encontros com atividades, utilizando-se várias técnicas artísticas para expressar lembranças de suas experiências singulares, por meio da monotipia, da cianotipia, da fotografia, da pintura e do desenho, associadas com as respectivas narrativas contextualizadas a essas reminiscências e experiências. Toda a programação teve o objetivo de ampliar o conhecimento sobre a importância da Arte às adolescentes reclusas. Observou-se, com isso, que o exemplo arrasta e é uma forma eficiente de compartilhar, educar, refletir e mostrar saberes e conhecimentos.

Sob esta perspectiva, o pesquisador deste estudo, apresentou seus trabalhos artísticos com o tema de memórias e experiências, articulando texto/desenho, e comentou sobre os métodos utilizado, como também compartilhou o conhecimento das técnicas utilizadas na elaboração dos trabalhos artísticos propostos nas ações com as adolescentes, para colher e dar existência a essas memórias e experiências.

No final, os trabalhos artísticos foram apresentados na instituição, em uma exposição aberta ao público.

\section{Fundamento conceitual e teórico}

Considera-se fundamental conceituar algumas palavras e seus significados nos estudos teóricos utilizados para melhor compreender o desenvolvimento das atividades propostas para a ação com as adolescentes.

Partindo da palavra Arte como referencial teórico básico para a pesquisa de campo, encontramos a educadora de Arte, Ana Mae Barbosa (1991), pioneira nos estudos e reflexões sobre arte/educação no Brasil, que revela em seu livro A imagem no Ensino da Arte:

Arte não é apenas básico, mas fundamental na educação de um país que se desenvolve. Arte não é enfeite. Arte é cognição, é profissão, é uma forma diferente da palavra para interpretar o mundo, a realidade, o imaginário, e é conteúdo. Como conteúdo, arte representa o melhor trabalho do ser humano.

R. Inter. Interdisc. Art\&Sensorium, Curitiba, v.7, n.1, p. 001 - 015 Jan.- Jun. 2020 
Para Ana Mae Barbosa (1991), na Arte e na vida, memória e história são personagens do mesmo cenário temporal, mas cada uma se veste a seu modo. Relata que a história intelectual e formal usa a vestimenta acadêmica, enquanto a memória não respeita regras nem metodologias, é afetiva e revive a cada lembrança. (BARBOSA, 1991, p. 4). Nesse sentido, a Arte tem sua relevância na vida do homem, contribuindo para seu desenvolvimento e crescimento como ser humano. Uma outra maneira de considerar a Arte na vida das pessoas é citada por Fischer:

A Arte pode elevar o homem de um estado de fragmentação a um estado de ser íntegro total. A Arte capacita o homem a compreender a realidade e o ajuda não só a suportá-la como a transformá-la, aumentando-lhe a determinação de torná-la mais humana e mais hospitaleira para a humanidade. A Arte, ela própria, é uma realidade social. (FISCHER, 2002, p. 57).

Uma vez que a presente pesquisa ocorre num presídio, é importante considerar qual a função dessa instituição. Encontra-se resposta no texto de Danilo Patzdorf:

É uma instituição desconhecida por quase todos os brasileiros. Criada e gerida pelos governos federal e estadual, seu funcionamento silencioso nos faz esquecer de que as cadeias são tão públicas quanto as escolas e hospitais. (PATZDORF, 2016, p. 53).

Já Michel Foucault (2014) aponta que princípios fundamentais são conhecidos há quase 150 anos como máximas universais da boa "condição penitenciária", que ainda hoje se esperam efeitos tão impressionantes que nunca se efetivaram real e plenamente, como, por exemplo, alguns princípios:

\begin{abstract}
A detenção penal deve então ter por função essencial a transformação do comportamento do indivíduo [...]. A pena privativa de liberdade tem como objetivo principal a recuperação e a reclassificação social do condenado (Princípio da correção). A educação do detento é, por parte do poder público, ao mesmo tempo uma preocupação indispensável no interesse da sociedade e uma obrigação para o detento. (Princípio da educação penitenciária). (FOUCAULT, 2014, p. 264-5-6, grifo do autor).
\end{abstract}

Já a denominação de "artista-pesquisador-professor" configura um desdobramento de um artista em produzir, pesquisar e ensinar, quando sua ação deriva a orientar o aprendiz, quando investiga e indaga suas dúvidas, quando se desdobra pelo fato de falar de sua técnica, de sua forma de produzir, de suas referências teóricas, de suas reflexões críticas e questionamentos sobre sua própria produção, e quando, principalmente, desperta uma reflexão do processo artístico no outro.

Assim, considera-se o conceito das palavras "artista", "pesquisador", e "professor" em um recorte de profissionais que trabalham na área de Artes, aprofundando as derivações da tríade denominada artista-pesquisador-professor.

A definição de "artista-etc.", de Ricardo Basbaum, é um ponto de partida importante para entender o seu trabalho e o seu papel como artista:

Quando um artista é artista em tempo integral, nós o chamaremos de 'artistaartista'; quando o artista questiona a natureza e a função de seu papel como artista, escreveremos 'artista-etc.'. (BASBAUM, 2005).

Como definição de "professor", o autor Jesus (2013) apresenta como

aquele que organiza as experiências, tendo em conta metas, objetivos ou o programa da disciplina, torna-se pertinente questionar o tipo de experiências que este proporciona aos alunos. (JESUS, 2013, p. 33).

R. Inter. Interdisc. Art\&Sensorium, Curitiba, v.7, n.1, p. 001 - 015 Jan.- Jun. 2020 
Outro conceito de "professor" é considerado por Lampert (2015) em seu texto Tessituras sobre Arte e Arte Educação:

O professor precisa entender, compreender e saber para poder ensinar Arte, assim como o professor precisa produzir praticamente. (LAMPERT, 2015, p. 106).

Quanto à concepção da palavra "pesquisa", encontra-se nos textos da autora Rita Irwin, que expõe que o processo de investigação (pesquisa) torna-se tão importante quanto a representação dos resultados alcançados, e identifica dois processos:

Artistas se envolvem em investigações artísticas que os auxiliam a explorar questões, temas, ou ideias que inspiram sua curiosidade e sensibilidades estéticas. (IRWIN, 2013, p. 29).

E, como pesquisador, busca entendimento de pesquisa no conceito de Sumaya Mattar:

A pesquisa é, pois, compreendida como poderoso instrumento organizador do processo de ensino e aprendizagem,[...] que a aula, o currículo e o próprio processo educativo podem ser concebidos como campos de investigação e experimentação, capazes de gerar conhecimentos. (MATTAR, 2010, p.168).

Para Almeida (2009), em seu estudo com base nas respostas de entrevistados, para os artistasprofessores o criar e o ensinar inter-relacionam-se. Outro estudo em que se busca aporte teórico sobre a atividade de artista e professor está na tese de doutoramento, em Educação Artística, de Joaquim Alberto Luz de Jesus (2013), o qual assume como um exercício de autoanálise a formação do duplo professor-artista. Esse autor faz referência à citação de Larrosa (1994, p. 80): "aprender a ver-se, a dizer-se ou a julgar-se é aprender a fabricar o próprio duplo" e "sujeitar-se a ele" (JESUS, 2013, p.17).

Corroborando Jesus (2013), Thornton (2005), em seu artigo The Artist Teacher as Reflective Practitioner, relata que a construção de identidade do professor-artista inter-relaciona-se com três mundos distintos: o da arte, o da educação e o da educação artística. Considera que cada um detém um conjunto de práticas, história, cultura e literatura, que tem de ser assimilado pelo professorartista pelo exercício de autorreflexão.

Desta forma, sobre a identificação do artista, pesquisador e professor em uma só unidade, conforme abordado pelas referências teóricas pesquisadas, constata-se que há muitas questões que ainda precisam ser solucionadas para que o artista e o professor possam exercer uma única função que contemple essas três atividades.

Como conceito de experiência, utiliza-se a do filósofo John Dewey. Em seus textos Arte como experiência e Ter uma experiência, Dewey (2012) contextualiza dois tipos de experiência: o primeiro trata-se de uma experiência incompleta, segmentada e superficial, e o segundo, de outra experiência, considerada "singular".

Muitas vezes, porém, a experiência vivida é incipiente. As coisas são experimentadas, mas não de modo a se comporem em uma experiência singular. Há distração e dispersão; o que observamos e o que pensamos, o que desejamos e o que obtemos, discordam entre si. (DEWEY, 2012, p.109).

Em uma experiência considerada singular, segundo Dewey, o percurso completa-se em tempo e espaço de uma "realização perfeita" de algo pensado ou imaginado. Ambas as experiências podem ocorrer simultaneamente. Mas o que as diferencia são os acontecimentos excepcionais que diferem dos outros porque são expressivos, significativos, e têm qualidades que não são comuns, como em uma experiência incipiente.

R. Inter. Interdisc. Art\&Sensorium, Curitiba, v.7, n.1, p. 001 - 015 Jan.- Jun. 2020 
De acordo com Dewey (2012), a experiência, essa negociação consciente entre o eu e o mundo, é uma característica irredutível da vida, e não há experiência mais intensa que a Arte. Portanto, o ponto de partida da filosofia deweyana da Arte é que, "por ser a realização de um organismo em suas lutas e conquistas em um mundo de coisas, a experiência é a Arte em estado germinal" (DEWEY, 2012, p. 84). Kaplan (2012) afirma, na Introdução do livro Arte como Experiência, de Dewey, que o produto artístico e a obra de arte constituem uma díade fundamental na filosofia de arte de Dewey. Por outro lado, a autora Almeida (2009) utiliza o sentido de experiência com base em Heidegger (1987), ou seja, a experiência com o que nos afeta e nos transforma, e, em busca de respostas, propõe:

Numa palavra, queria discutir a concretude de um trabalho feito por quem é artista e professor; ouvir a voz dessas pessoas: saber não só o que pensam sobre ensinar arte, mas também como ensinam e como se sentem ao fazê-lo, o que pretendem. (ALMEIDA, 2009, p. 23).

Na obra do filósofo Bergson (2010), encontra-se os conceitos de memória e sua importância nas reminiscências das experiências vivenciadas como forma de relembrar e trazer para o presente os acontecimentos singulares. Para evocar o passado em forma de imagem, é preciso poder abstrair-se da ação presente, é preciso saber dar valor ao inútil, é preciso querer sonhar.” (BERGSON, 2010, p. 90).

Quanto a metodologia, foi com base na $\mathrm{A} / \mathrm{r} / \mathrm{tografia}$, que é uma forma de representação que privilegia tanto o texto (escrito) quanto a imagem (visual), cujo acrônimo: A (Artist) é artista, $r$ (research) é pesquisador, $t$ (teacher) é professor, e grafia, escrita e representação. É um método que propicia ao artista pesquisar, ensinar algo provocador para repensar, reviver e refazer suas práticas estéticas pedagógicas. Segundo a educadora de arte, Rita L. Irwin expõe:

\begin{abstract}
A/r/tografia não apenas reconhece o papel de cada individuo, mas também possibilita que todos nós tenhamos um momento de imaginação ao apreciarmos e entendermos que os processos e produtos envolvidos na criação da Arte, não importando se são objetos ou tarefas profissionais, são formas exemplares de integração entre saber, prática e criação. (IRWIN, 2008, p. 92).
\end{abstract}

\title{
3 O lugar do outro
}

A programação de atividades planejadas para o desenvolvimento de processos artísticos utilizou simultaneamente a narrativa de experiências singulares vivenciadas pelas próprias adolescentes ocorridas em suas vidas e a vinculação de imagens/desenhos/pinturas com essas contextualizações. Buscou-se rememorar essas lembranças na representação e elaboração de conexões entre imagens/desenhos por meio do processo artístico.

As adolescentes relataram lembranças significativas da sua memória. Ilustram-se algumas respostas: "em uma festa eletrônica, que estava eu e o meu marido, [...], e nós sentamos no capô do carro, aí ele começou a falar coisas lindas e disse que me amava; quando minha cachorra pulou no meu colo e me sujou toda". Constata-se que as lembranças envolvem principalmente familiares e alguns objetos e animais. Observa-se que essas lembranças escritas são ressignificadas por imagens por meio dos processos artísticos desenvolvidos nas micropráticas, conforme alguns exemplos a seguir representados (Figuras 1, 2 e 3).

R. Inter. Interdisc. Art\&Sensorium, Curitiba, v.7, n.1, p. 001 - 015 Jan.- Jun. 2020 


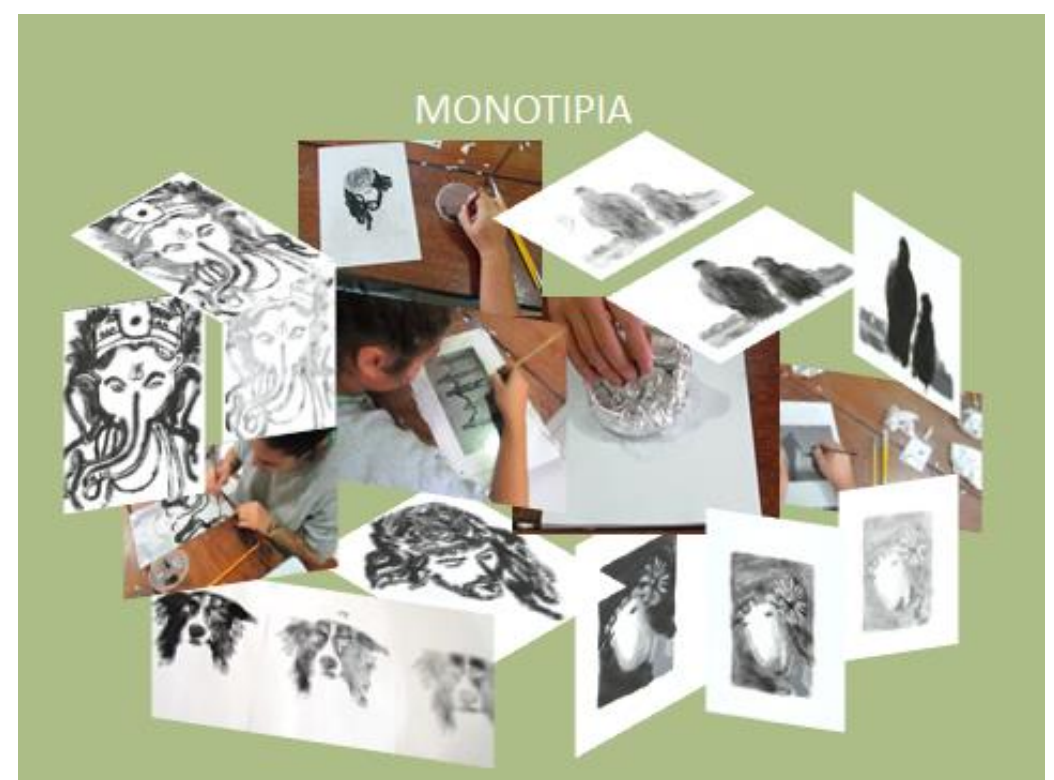

Fig. 1 - Monotipia -Técnica: Óleo sob papel sulfite - Dimensões: 20x30 cm - Ano: 2017. Fonte: Fotografia do autor.

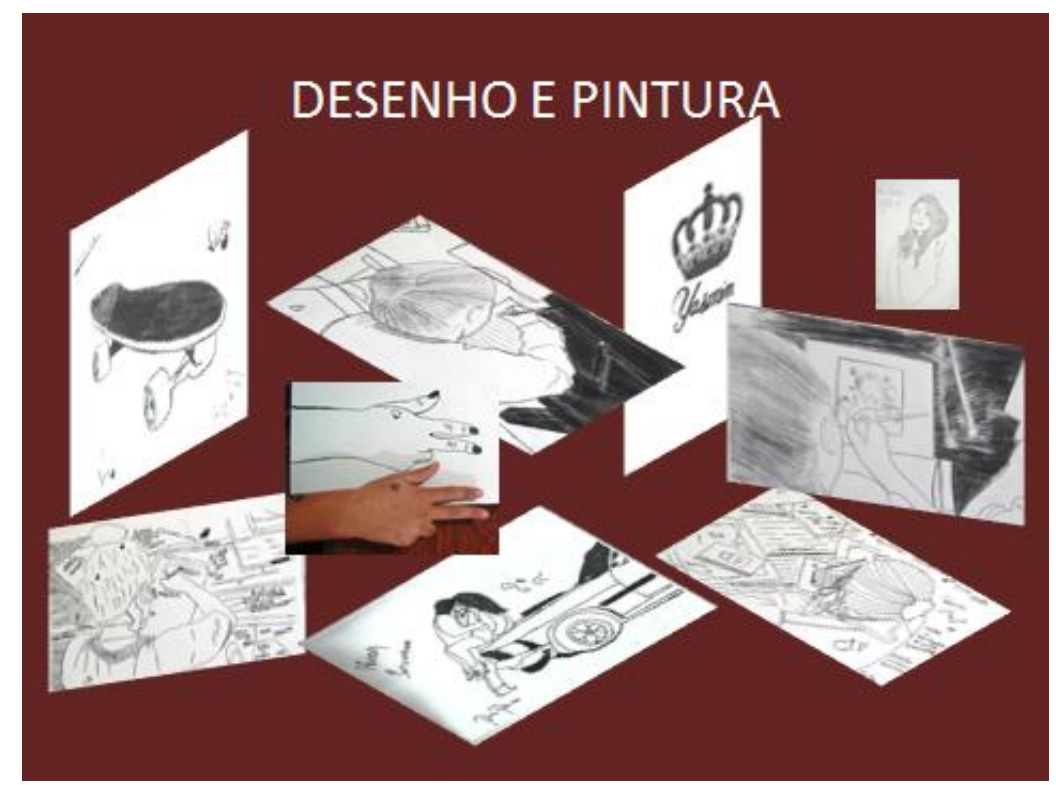

Fig. 2 - Microprática -Técnica: Desenho e pintura - Dimensões: 20x30 cm - Ano: 2017. Fonte: Fotografia do autor.

R. Inter. Interdisc. Art\&Sensorium, Curitiba, v.7, n.1, p. 001 - 015 Jan.- Jun. 2020 


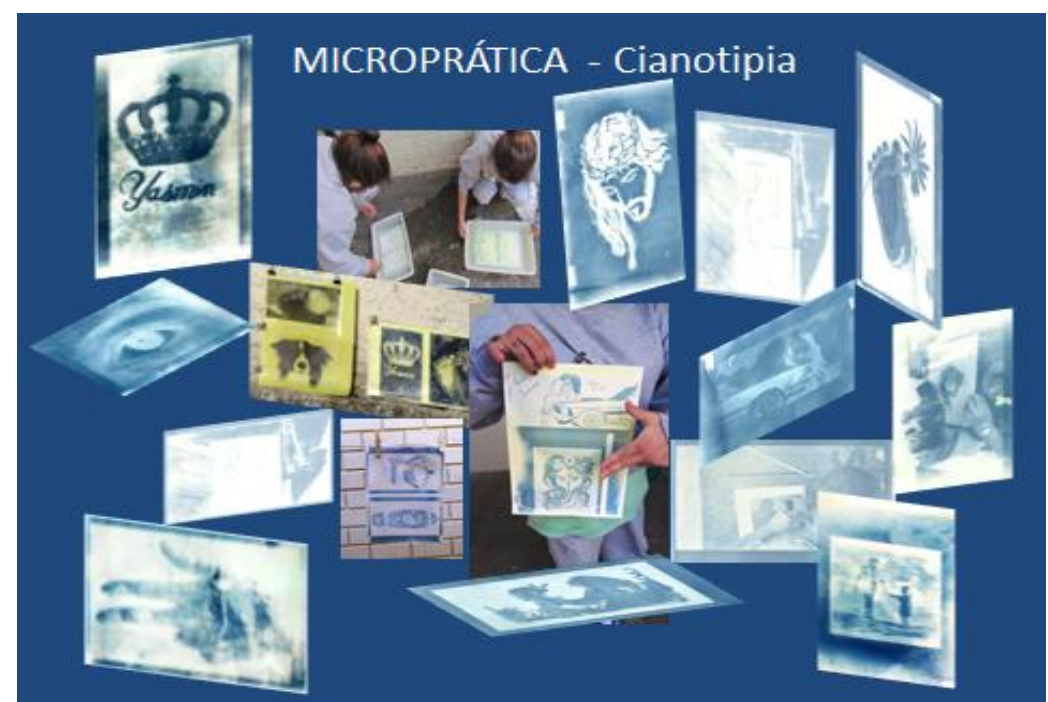

Fig. 3 - Microprática -Técnica: Cianotipia- Dim.: 20x30 cm - Ano: 2017. Fonte: Fotografia do autor.

A partir das imagens construídas, perguntou-se: O que representa essa imagem agora ressignificada por um processo artístico? Alguns exemplos de depoimentos:

[...] me senti não muito bem, pois sinto muita falta e saudade da minha família, e a correntinha que eu ganhei da minha mãe, que já faleceu, e também sinto muita, muita falta dela; representa minhas melhores lembranças, com a minha família; o significado das minhas imagens foi mais a minha família, foi o amor por eles. (1305-2016).

Nesses depoimentos, verifica-se que as lembranças boas e ruins fazem parte das recordações, observa-se que as imagens escolhidas expressam esses momentos do passado, que são revividos no presente pelo processo artístico.

As imagens produzidas propiciam conexões com suas memórias? Citam-se alguns exemplos de respostas das adolescentes:

[...] sim, eu relembro das loucuras e dos bons momentos, das festas e dos amigos; sim, senti uma imensa saudade da minha mãe, da noite de quando eu ia à igreja com a minha família; sim, representa eu e minha mãe porque eu não vejo ela já faz 15 anos e eu amei; me deixou muito emocionada; me fizeram enxergar e lembrar tudo o que vivi; representa uma lembrança de quando minha filha nasceu, aquele pezinho pequeno dela, e a tatoo em homenagem para ela com o seu nome e com uma coroa de princes $a[\ldots]$ (20-05-2016).

Constatou-se que as conexões são estabelecidas entre a imagem e os momentos relembrados pelas participantes.

Foi solicitado para as adolescentes participantes que relatassem seus depoimentos com relação aos resultados alcançados com as técnicas de monotipia e cianotipia e o que as imagens representavam. As adolescentes posicionaram-se:

Porque eu usei desenhos que vêm das minhas lembranças do passado. E foi bom porque usei desenhos das coisas de que eu mais gosto e lembranças que me marcaram; de fazer relembrar bastante a minha família; me fizeram enxergar e lembrar tudo o que vivi; representa uma lembrança de quando minha filha nasceu aquele pezinho pequeno dela, e a tatoo em homenagem para ela com o seu nome e

R. Inter. Interdisc. Art\&Sensorium, Curitiba, v.7, n.1, p. 001 - 015 Jan.- Jun. 2020 
com uma coroa de princesa [...];representa minhas lembranças da minha cachorra, do meu pai, da minha mãe; me deixou muito emocionada; Coisas que vão ficar na minha memória para sempre; sim; tenho muitas saudades do mundão; sim, principalmente aquela do capô do carro, me traz boas memórias. . (27-05-2016).

Assim relataram algumas conexões entre imagem, experiência e reminiscência. Observa-se o relato de lembrança de um cachorro de uma adolescente, que, segundo Baudrillard (2004, p.97), "representa o mais belo animal doméstico e que constitui uma espécie intermediária entre os seres e os objetos". São experiências registradas em suas memórias como momentos especiais e inesquecíveis.

Quanto aos desenhos e pinturas que desenvolveram nas ações, as adolescentes responderam:

[...] enquanto estava desenhando a minha tatoo, veio na minha memória o dia que eu fiz ela. Foi uma coroa de princesa com o nome da minha filha embaixo Yasmin.... Fiz um desenho que relembrei de um ótimo momento que eu tive com o amor da minha vida; me trouxe boas lembranças; foi uma sensação ótima. Com um aroma de felicidade; sim, os meus desenhos são todos lembranças, que me dava muita saudade da minha família e dava uma coisa assim que dava vontade de sair correndo atrás das minhas lembranças! (17-06-2016).

Ao desenhar as suas imagens escolhidas, muitas das adolescentes expressaram que sentiram emoção, saudade e lembranças das suas vivências. Nesse sentido, Lela Martorano considera:

O papel da memória é o de fazer coincidir duas visões, ou dois atos 'bioquímicos', o ver e o lembrar. Mais uma vez surgem as passagens entre as linguagens artísticas, entre o olhar e a memória, a realidade e a recordação. (MARTORANO, 2000, p. 24).

A interligação entre contextualização, monotipia, cianotipia, fotografia e desenho com as lembranças das memórias das adolescentes estão presentes na observação e reflexão das participantes e no fazer artístico. São depoimentos e trabalhos que revelam as sensibilidades e percepções de suas experiências vivenciadas, e que estão marcadas em suas memórias.

\section{Experiências como artista-pesquisador-professor}

Como artista, o autor deste estudo compartilhou e apresentou trabalhos às adolescentes em conflito com a lei, como o Trabalho de Conclusão de Curso (TCC), Memórias Afetivas - Museu dos Objetos, (2013), em que contextualizou por palavras e desenhos suas memórias e experiências, as quais disponibilizou às adolescentes para uma reflexão como um fio condutor entre suas memórias e as das participantes. Segundo Walter Benjamin (1985, p.154), "o exemplo arrasta consigo um índice secreto que o remete à salvação". Nesse sentido, utiliza-se como exemplo a imagem, como vetor de referências para estimular as reminiscências do outro, por meio dos desenhos e das narrativas contextualizadas no livro Museu dos Objetos (ROCHA, 2013), conforme Figura 4 e de Memórias Afetivas (Figura 5). 

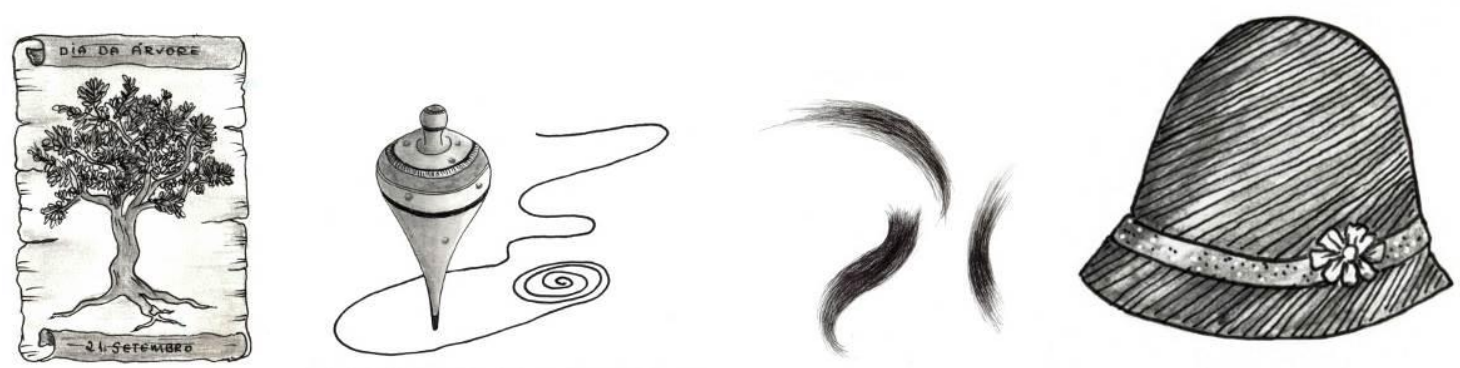

Figura 4 - Museus dos Objetos. Desenhos a nanquim. Dim.10 x15 cm. Ano: 2013.

Fonte: Elaborado pelo Autor.

ÁRVORE - Meu primeiro desenho em homenagem ao Dia da Árvore aos 9 anos, minha primeira decepção como artista por ser desacreditado pela professora como autor.

PIÃO - Um dos meus brinquedos prediletos: sua forma, seu equilíbrio, sua cor e sua rotação me fascinavam.

CABELOS - Vestígios dos meus três amores: filhos Maico, Luciana e esposa Marlene (que partiu).

CHAPÉU - Símbolo que marcou o sacrifício da perda por duas vezes dos lindos cabelos da minha amada até seus últimos dias. (ROCHA, 2015, p.750).

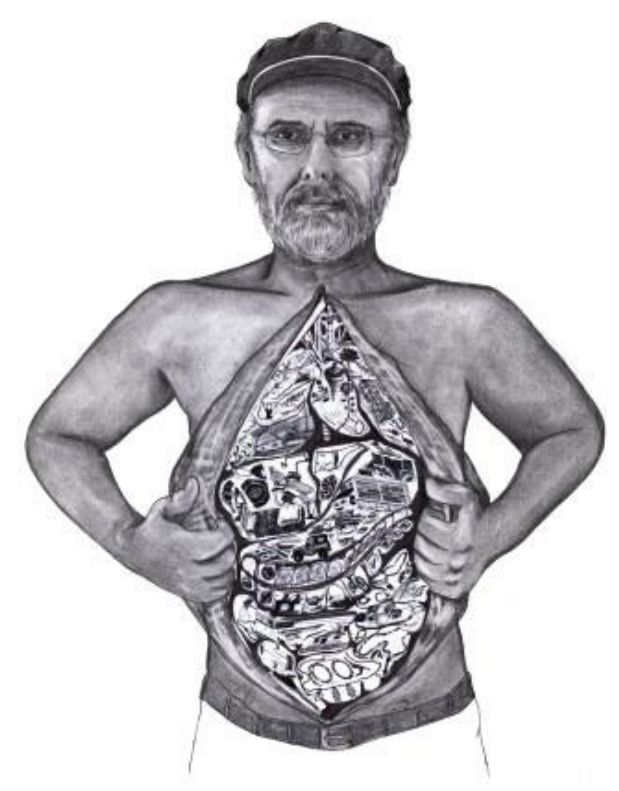

Figura 5 - Título: Memórias Afetivas - Técnica: Lápis HD e nanquim - Dim.: 40 x 30 cm - Ano: 2013. Fonte: Obra do autor.

Os desenhos são símbolos que despertam reminiscências, os quais, contextualizados por palavras, completam o ciclo de experiências específicas vivenciadas pelo autor. Os textos narrados partem de experiências de um contexto em que se deram os momentos que circundaram esses objetos afetivos identificados no passado, agora presente. Baudrillard considera os objetos abstraídos de sua função e relacionados ao indivíduo:

R. Inter. Interdisc. Art\&Sensorium, Curitiba, v.7, n.1, p. 001 - 015 Jan.- Jun. 2020 
Neste nível todos os objetos possuídos participam da mesma abstração e remetem uns aos outros na medida em que somente remetem ao indivíduo. Constitui-se pois em sistema graças ao qual o indivíduo tenta reconstruir um mundo, uma totalidade privada. (BAUDRILLARD, 2004, p. 94).

$\mathrm{O}$ artista apresenta sua subjetividade com relação ao que pensa, sente e como trabalha em direção à subjetividade das adolescentes, como forma de convite e demonstração de um caminho para elas encontrarem novos sentidos e olhares sobre o mundo, e de serem elas mesmas.

Outro exemplo como artista são os retratos, elaborados pelo autor para as adolescentes como valorização da autoestima destas e agradecimento na participação das atividades desenvolvidas, sendo esses retratos realizados fora dos encontros e apresentados somente na exposição final dos trabalhos como presente e elemento-surpresa (Figura 6). Esses retratos fazem parte da experiência e produção artística do pesquisador, mesclando-se com a atividade proposta às adolescentes no $7^{\circ}$ encontro "Desenhando em linhas. Apresentam-se alguns exemplos de retratos das participantes elaborados pelo autor:

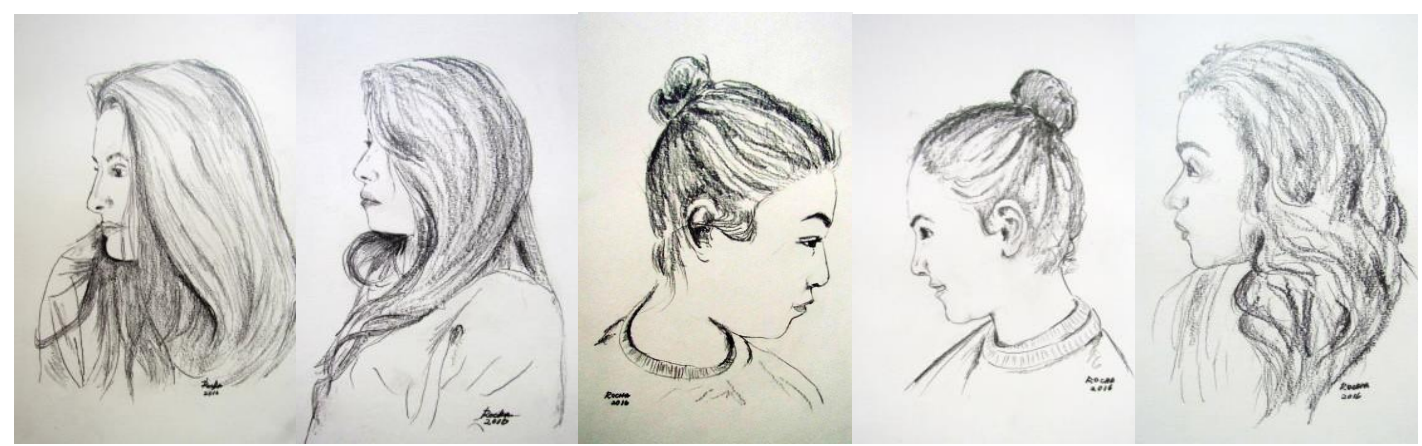

Figura 6 - Título: Retratos das adolescentes. Técnica: Lápis HD - Dim.: 40 x 30 cm. Ano: 2016. Fonte: Obra do autor.

Procurou-se, nas respostas e nos resultados dos trabalhos artísticos das adolescentes, encontrar significados, percepções, reflexões, críticas e observações decorrentes das atividades desenvolvidas nos encontros. Encontra-se, em Walter Benjamim (1995, p. 239), relação com essas recordações: "Quem pretende se aproximar do próprio passado soterrado deve agir como um homem que escava”. Essas lembranças são desdobradas e contextualizadas, e expressas nas micropráticas.

As respostas e os trabalhos desenvolvidos denotaram a relação das narrativas com as imagens elaboradas. Nesse sentido, buscam-se novos caminhos e maneiras de pensar, de entender, de refletir, de procurar, de questionar e obter novos conhecimentos e experiências que a Arte propicia. Assim, a Arte possibilita ver e perceber novos horizontes e conhecimentos.

Verificou-se que a reflexão de si como artista-pesquisador-professor provoca um deslocamento de conscientização da própria identificação, pois, conforme Bourdieu apud Jesus,

\footnotetext{
Nada me tornaria mais feliz do que ter conseguido que alguns dos meus leitores e leitoras reconhecessem as suas experiências, as suas dificuldades, as suas interrogações, os seus sofrimentos, etc., nos meus.... (BOURDIEU, 2005, p. 119 apud JESUS, 2013, p. 23).
}

A percepção de artista agora como pesquisador e professor de Ensino das Artes Visuais ganha novos horizontes e profundidade em vários sentidos. Essa tridimensionalidade de função em uma só identidade permite avançar e expandir a própria imagem como educador de ensino de Artes Visuais e avançar sobre as dificuldades que rodeiam e desafiam os artistas-pesquisadores-professores. 


\section{Considerações finais}

Este pesquisador indaga-se sobre o que o levou a pesquisar sobre o tema Produzir, Pesquisar e Ensinar Artes Visuais em uma instituição de reclusão para adolescentes em conflito com a lei. Como artista, utiliza o processo artístico para compartilhar e expressar suas memórias e experiências como meio de reviver, relembrar, rememorar, no presente, momentos singulares vividos. E com objetivo de partilhar essa percepção e reflexão da Arte, procura levar essas experiências a locais para onde a Arte não está presente, fora dos currículos escolares e acadêmicos. Sempre pensou que, por meio do conhecimento do Ensino das Artes Visuais, poderia expandir e aprofundar percepções e reflexões críticas sobre a essência de ser artista, pesquisador e professor. Essa busca levou-o a pesquisar o sentido de ser artista e ser professor ao mesmo tempo. E, nessa direção, agora encontra-se em um dos lugares que procura: ser artista-pesquisador-professor para adolescentes em conflito com a lei, tolhidas de liberdade em uma instituição pública fechada.

Nas atividades pedagógicas programadas e desenvolvidas com as adolescentes, observou-se que a narrativa de experiências singulares e reminiscências são desenraizadas e recapturadas pela monotipia, cianotipia, fotografia e desenho.

Verificou-se que a a/r/tografia possibilitou redimensionar a construção de conhecimentos por meio dos processos artísticos desenvolvidos nas micropráticas, nos dois sentidos, tanto para a experiência como artista-pesquisador-professor como para as adolescentes do grupo de estudo.

Constatou-se, pelas respostas das perguntas e pelas imagens elaboradas pelas adolescentes, que o objetivo proposto das ações foi alcançado satisfatoriamente, manifestando e envolvendo uma carga enorme de poesia, como nesta síntese de depoimentos:

Todos os trabalhos que eu fiz me lembraram de todos os momentos lindos que expressei nas folhas, pude também voltar ao passado e sentir aquele gostinho gostoso de felicidade que já vivi. Tenho orgulho de ter aprendido uma coisa que eu talvez nunca iria ter aprendido lá no mundão. (24-06-2016).

Observou-se, nas respostas das adolescentes, percepções, reflexões, emoções, saudades, experiências e lembranças de um tempo que passou, mas que ainda está presente na memória. E constata-se que o processo artístico proporciona uma viagem, revivendo e ressignificando esses momentos. Dessa forma, as ações desenvolvidas proporcionam novas possibilidades de reconfigurar memórias e experiências, não como forma de passatempo, hobby, terapia, ou teoria com acuidade, mas de percepções e emoções únicas ao relembrar uma parte singular da vida que está registrada na memória, expressa em uma atmosfera calorosa, mesmo em um ambiente prisional. Assim, o trabalho artístico possui e carrega significado e expressividade, não como um desenho "bonito" ou em busca de legitimidade de artista. Buscou-se uma visão sobre a Arte em diversas linguagens, para que as adolescentes pudessem, além de refletir sobre seus trabalhos, apreciá-los nessas linguagens, como expressão criadora e como aprendizagem das Artes, bem como melhorar a autoestima e aprimorar o senso crítico. Resultou, assim, em registros que configuram fragmentos de diários de suas memórias e experiências, como em um lexigrama, cujas emoções e percepções estão conectadas nos seus trabalhos artísticos.

As imagens e os textos das lembranças e experiências são como uma passagem no tempo; cada uma das adolescentes volta a reviver o passado como um momento de liberdade, em que as narrativas e as imagens elaboradas registram essa viagem, embora estejam reclusas. É como reconstituir uma identidade que foi danificada. As lembranças são a história dos seus mundos quando revividas e

R. Inter. Interdisc. Art\&Sensorium, Curitiba, v.7, n.1, p. 001 - 015 Jan.- Jun. 2020 
ressignificadas. E a potência do ensino da Arte como experiência propicia retomar e revisitar essas reminiscências.

O compartilhamento das memórias e experiências entre o pesquisador e o grupo de estudo está nos resultados dos trabalhos realizados pelas adolescentes, cuja interação nos encontros demonstra essa conexão satisfatória de entendimento para alcançar os objetivos das micropráticas.

Verifica-se que a apresentação da poética e da produção artística do pesquisador às participantes das micropráticas estabelece um vínculo direto de uma experiência que nenhum livro ou imagem virtual substitui.

As conversas e a experiências práticas entre o artista-professor-pesquisador e as participantes passam de imediato, propiciando o entendimento das práticas artísticas desenvolvidas com as adolescentes. A apresentação de como foi feito o trabalho artístico, o que representa, qual seu significado, qual a importância que tem como experiência, são curiosidades e questionamentos que levaram as adolescentes a conhecer as respostas do artista-pesquisador-professor.

Eisner (2011, p.22) comenta que: "El saber humano es una forma construida por la experiencia y, en consecuencia, un reflejo tanto de la mente como de la naturaliza: el saber se hace, no simplesmente se descubre“.

$\mathrm{O}$ encontro sobre os trabalhos apresentados do pesquisador como artista propiciou às participantes a refletirem e observarem que o artista-pesquisador-professor também tem suas ressignificações de suas experiências e lembranças boas ou ruins, identificadas na poética e nos significados dos trabalhos artísticos realizados. Por isso, utiliza a Arte como meio para expressar sua maneira de pensar e estar no mundo. Um dos exemplos de percepção e observação pelas adolescentes foi sobre os livros de fotografias de Sebastião Salgado, Retratos de crianças do êxodo (2000) e Terra (1997), que mostram a fragilidade das crianças que passam fome e vivem na miséria em alguns países do mundo, levando-as a refletirem e observarem que existem situações bem piores às que estão vivenciando, conforme seus relatos.

Como respostas às reflexões críticas, buscou-se, além das obtidas e observadas, novas possibilidades de reconfigurar o processo artístico no Ensino das Artes Visuais com a identidade de artista-pesquisador-professor, para levar as participantes a apropriarem-se do conhecimento em Arte tanto como forma de perceber e interpretar os trabalhos artísticos produzidos quanto o próprio mundo. Desta forma, amplia e renova o conhecimento, reflexão crítica e visão de Artista, Pesquisador e Educador das Artes Visuais, no sentido de ser uma semente da Arte em espaços não escolares e acadêmicos, e como agente para romper as barreiras do conhecimento da Arte.

\section{REFERÊNCIAS}

ALMEIDA, C. M. C. Ser Artista, Ser Professor: razões e paixões do ofício. São Paulo: Editora USP, 2009.

BARBoSA, A. M. T. B. A imagem no ensino da Arte: anos oitenta e novos tempos. São Paulo: Editora Perspectiva, 1991.

BASBAUM, R. I love etc-artists. Texto originalmente publicado em inglês, parte do projeto The Next Documenta Should Be Curated by an Artist, traduzido para o português em Políticas institucionais, práticas curatoriais, organizado por Rodrigo Moura (Belo Horizonte, Museu de Arte da Pampulha, 2005). Dossiê do artista. Arquivo 30. ${ }^{a}$ Bienal Ricardo Basbaum, um artista-etc. Disponível em: $<$ http://bienal.org.br/post.php?i=551>. Acesso em: 3 fev. 2016.

R. Inter. Interdisc. Art\&Sensorium, Curitiba, v.7, n.1, p. 001 - 015 Jan.- Jun. 2020 
BASBAUM, R. Manual do Artista - etc. Texto: O Artista como pesquisador. R.J: Beco do Azougue, 2013.

BAUDRILLARD, J. O sistema de objetos. S.P. Ed. Perspectiva, 2004.

BENJAMIN, W. Obras Escolhidas. Rua de mão única. S. P.: Ed. Brasiliense, 1995.

BERGSON, H. Matéria e memória: ensaio sobre a relação do corpo com o espírito. 4. ed. S.P.: WMF Martins Fontes Ltda, 2010.

DEWEY, J. Arte como experiência. S.P.: Ed. Martins Ed. Livraria Ltda., 2012.

EISNER, E. El ojo ilustrado. Indagación cualitativa y mejora de la práctica educativa. Barcelona: Paidós Educador. Libraria Paidos, 2011.

FISCHER, E. O ensino de arte e formação de docentes. S.P.: Ed. A, 2002.

IRWIN, R. A/r/tografia: uma mestiçagem metonímica. In: BARBOSA, Ana Mae; AMARAL, Lilian. (Org.). Interterritorialidade, mídias, contextos e educação. S.P.: Edições SESCSP, 2008. p. 87-104.

JESUS, J. A. L. (In)visibilidades: um estudo sobre o devir do professor-artista no ensino em artes visuais. 2013. 260 p. Tese (Doutorado em Educação Artística)- Faculdade de Belas Artes, Univ. do Porto, Porto, 2013.

KAPLAN, A. Introdução. In: DEWEY, John. Arte como experiência. S.P.: Ed. Martins Ed. Livraria Ltda., 2012. p. 7-49.

LAMPERT, J. Tessituras sobre Arte e Arte Educação, ou: sobre deambulações no ensino de arte. In: OLIVEIRA, Marilda Oliveira de; HERNANDEZ, Fernando (Org.). A formação do professor e o ensino das artes visuais. 2. ed. Santa Maria: UFSM, 2015, p. 103-118.

MARTORANO, L. Da memória e seus lapsos. 2000. 160 f.Trabalho de Conclusão de Curso (Bacharel em Pintura e Gravura) - CEART- UDESC- SC - Florianópolis, 2000.

MATTAR, S. Sobre Arte Educação: entre a oficina artesanal e a sala de aula. Campinas: Papirus, 2010.

PATZDORF, D. Corpos encarcerados: breves reflexões sobre o ensino de arte a partir de uma experiência penitenciária. In: MATTAR, Sumaya, ROIPHE, Alberto (Org.). Arte e Educação: ressonâncias e repercussões. S.P. ECA 2016. p. 53-61.

ROCHA, J. C. Memórias afetivas: museu dos objetos. 2013. 55 p. (v.1), 72 p. (v.2). Trabalho de Conclusão de Curso em Artes Visuais - CEART, UDESC, Florianópolis, 2013.

ROCHA, J. C. Reflexões sobre a experiência: paisagem cartográfica do artista/pesquisador. In: ANPAP, 24, Santa Maria, 2015. Anais... ANPAP, Santa Maria, 2015.

SALGADO, S. Retratos de Crianças do êxodo. São Paulo: Companhia das Letras, 2000.

. Terra. São Paulo: Companhia das Letras, 1997.

THORTON, A. The Artist Teacher as Reflective Practitioner. Chicago: Intellect Bristol, 2005.

R. Inter. Interdisc. Art\&Sensorium, Curitiba, v.7, n.1, p. 001 - 015 Jan.- Jun. 2020 